\title{
Erratum to: Plasma and saliva miR-21 expression in colorectal cancer patients
}

\author{
A. A. Sazanov ${ }^{1,2}$ - E. V. Kiselyova ${ }^{3}$ - A. A. Zakharenko ${ }^{3}$ - M. N. Romanov ${ }^{4}$. \\ M. I. Zaraysky ${ }^{1}$
}

Published online: 28 December 2016

(C) Institute of Plant Genetics, Polish Academy of Sciences, Poznan 2016

Erratum to: J Appl Genetics

DOI:10.1007/s13353-016-0379-9

The Acknowledgement section in the original version is missing. Given in the following is the complete acknowledgement statement.

Acknowledgements Michael N. Romanov is supported by a grant of the Government of Russian Federation (Contract No. 14.W03.31.0013).

The online version of the original article can be found at http://dx.org. doi/10.1007/s13353-016-0379-9.

A. A. Sazanov

alexei.sazanov@technolog.edu.ru

1 Department of Clinical Laboratory Diagnostics with a course of Molecular Medicine, First Pavlov State Medical University of St. Petersburg, 6/8 Lev Tolstoy Street, St. Petersburg 197022, Russia

2 Department of the Molecular Biotechnology, Saint-Petersburg State Technological Institute (Technical University), St. Petersburg, Russia

3 Department of Surgery and Emergency Medicine, First Pavlov State Medical University of St. Petersburg, St. Petersburg, Russia

4 School of Biosciences, University of Kent, Canterbury, UK 